Abstracta Iranica Abstracta Iranica

Revue bibliographique pour le domaine irano-aryen

Volume 26 | 2005

Comptes rendus des publications de 2003

\title{
Agriculture in Qajar Iran. Washington D.C., Mage Publishers, 2003, 692 p., bibl., index, 97 ill.
}

\section{Jean-Pierre Digard}

\section{OpenEdition \\ 9 Journals}

Édition électronique

URL : http://journals.openedition.org/abstractairanica/2743

ISSN : 1961-960X

\section{Éditeur :}

CNRS (UMR 7528 Mondes iraniens et indiens), Éditions de l'IFRI

\section{Édition imprimée}

Date de publication : 15 mai 2005

ISSN : 0240-8910

\section{Référence électronique}

Jean-Pierre Digard, « Agriculture in Qajar Iran. Washington D.C., Mage Publishers, 2003, 692 p., bibl.,

index, 97 ill. », Abstracta Iranica [En ligne], Volume 26 | 2005, document 222, mis en ligne le 08

décembre 2005, consulté le 25 septembre 2020. URL : http://journals.openedition.org/

abstractairanica/2743

Ce document a été généré automatiquement le 25 septembre 2020.

Tous droits réservés 


\title{
Agriculture in Qajar Iran. Washington D.C., Mage Publishers, 2003, 692 p., bibl., index, 97 ill.
}

\author{
Jean-Pierre Digard
}

1 Jusqu'au début du $20^{\mathrm{e}} \mathrm{s}$., l'Iran présentait une économie d'agriculture de subsistance, qui entretenait un commerce chroniquement déficitaire avec l'Inde, déficit compensé (mais pas toujours) par les exportations de certains produits vers la Russie et la Turquie ottomane. $80 \%$ de la population iranienne était alors agricole. Selon une opinion dominante, l'agriculture iranienne du $19^{\mathrm{e}} \mathrm{s}$., pourtant période de grand changement, représentait un secteur en stagnation, cause d'appauvrissement de la population et origine de la dépendance économique de l'Iran qui allait suivre. Mais, pour l'A., cette opinion a le tort de se fonder principalement sur les chiffres des exportations, déficitaires, et surtout de méconnaître la fonction interne, structurante, de l'agriculture. En effet, seuls trois chercheurs - A. K. S. Lambton, Vahid F. Nowshirvani et Gad Gilbar - se sont, selon lui, intéressés aux aspects structurants de l'agriculture iranienne et à leur rôle dans la transition d'une agriculture vivrière à une agriculture commerciale à partir de 1850. C'est donc dans le but de savoir si la seconde moitié du $19^{\mathrm{e}} \mathrm{s}$. a été une période de changements structurels pour l'agriculture iranienne (comme le pense Nowshirvani) ou bien si elle a simplement vu l'accentuation d'évolutions déjà en cours antérieurement que W.F. entreprend de dresser un vaste tableau, solidement documenté, de l'agriculture iranienne à l'époque qâjâre.

2 Après avoir décrit les conditions de commercialisation des produits agricoles (partie I) et d'accès à la terre, notamment à travers les relations villes-villages (II), puis les structures sociales (III) et les conditions de vie de la population rurale (IV), l'A. passe en revue les principales techniques agricoles (V) et plantes cultivées (VI), sans oublier les fibres (soie, laine, coton...), les espèces addictives (opium, tabac, thé), les gommes, les plantes tinctoriales, les épices et l'eau de rose. L'élevage (VII) fait un peu figure de parent pauvre. Les touches finales sont apportées par les activités non agricoles 
(poterie, chaussures, tapis, charbon... VIII) et l'exploitation des ressources forestières et halieutiques (IX).

3 A lire W.F., il apparaît bien que vers 1850 se situe un tournant d'une agriculture prémarchande à une agriculture commerciale. S'est-il agi d'un véritable changement structurel (comme le pense Nowshirvani) ou bien de l'évolution de structures déjà existantes ? Dès 1840, l'économie iranienne était déjà intégrée, avec des échanges interrégionaux. Mais ces échanges étaient freinés, moins par un manque d'offre que par un manque de demande et par des coûts de transport élevés réduisant les bénéfices, dûs surtout à l'insuffisance des voies de communication. Ces obstacles subsistaient en 1900 . Entre 1860 et 1910 , dans certaines parties ou secteurs de l'Iran, la faiblesse des échanges inter-régionaux a été compensée par le développement des échanges internationaux lié à la présence des Européens et des Russes.

Le niveau de vie des paysans dépendait beaucoup, directement, des facteurs naturels. Pour augmenter leur production, les villageois disposaient de plusieurs moyens: 1) augmenter leurs terres (en surface disponible ou par des apports d'eau et de travail); 2) augmenter leur productivité à l'unité de surface (par des engrais); 3) pratiquer des cultures plus rémunératrices (opium, coton, soie, tabac, fruits);4) développer des activités non agricoles (tapis) - moyens dont la mise en œuvre nécessitait des capitaux, soit indigènes (des bāzārī pour l'opium), soit étrangers (pour des productions comme la soie ou le coton dont l'exportation était juteuse). Les premières victimes des spéculateurs étaient les paysans qui, en cas d'incident de parcours, se retrouvaient sans terre (Hošnešin) et/ou ouvriers agricoles (mozdūr). La parade à cette fragilisation résidait dans le repli prudent sur des cultures vivrières, ce qui a contribué à figer le système, à encourager le conservatisme les propriétaires, à éloigner les investisseurs et à retarder la marchandisation de l'agriculture. C'est aussi pourquoi l'Iran rural a longtemps présenté, bien après 1925, l'aspect d'une mosaïque d'îlots d'ancien système et de larges pans intégrés à l'économie mondiale.

Voilà donc, au total, sur un domaine relativement négligé, un livre documenté, utile et intéressant, mais malheureusement entaché de nombreuses imperfections - erreurs de transcription, lacunes bibliographiques, reproductions de gravures et de photographies trop petites et sans indication de sources... - qui diminuent le plaisir du lecteur.

\section{INDEX}

Thèmes : 4.2.1. Safavides et Qâjârs

\section{AUTEURS}

JEAN-PIERRE DIGARD

CNRS - Paris 